\title{
Corrupción: El cáncer que frena el desarrollo económico y social en el Perú. Una mirada desde el ejercicio del Derecho
}

César Augusto Nakazaki Servigón

Abogado por la Universidad de Lima. Miembro de la Comisión Revisora del Código Procesal Penal encargada por el Congreso de la República en el año 2000.

Miembro de la Comisión de Código Penal Alternativo del Colegio de Abogados de Lima. Profesor de los cursos de Derecho Penal Parte General, Derecho Penal Parte Especial y Derecho Procesal Penal de la Academia de la Magistratura del Perú. Profesor de Derecho Penal, Derecho Procesal Penal y Ética Profesional de la Facultad de Derecho de la Universidad de Lima. 


\section{RESUMEN:}

En esta ocasión, ADVOCATUS tuvo la oportunidad de entrevistar al doctor César Augusto Nakazaki Servigón, abogado con experiencia de casi tres décadas en litigios sobre las áreas de derecho penal y procesal penal. Asimismo, es considerado uno de los abogados más destacados del país, por participar en casos complejos dentro del sistema judicial peruano, como la defensa de tres expresidentes. En las siguientes líneas, se ofrece un breve análisis sobre la regulación de la corrupción en nuestro país, así como, la opinión de cómo se vienen llevando a cabo los procesos judiciales en el Perú.

\footnotetext{
ABSTRACT:

On this occasion, ADVOCATUS had the opportunity to interview César Augusto Nakazaki Servigón, a lawyer with almost three decades of experience in litigation in the areas of criminal law and criminal procedure. He is also considered one of the most prominent lawyers in the country, for participating in complex cases within the Peruvian judicial system, such as the defense of three former presidents.

In the following lines, the interviewee offered a brief analysis on the regulation of corruption in our country, as well as, the opinion of how judicial processes are being carried out in Peru.
}

\section{1. ¿Cómo puede usted explicar que existan semejantes niveles de corrupción tanto en países desarrollados como en países en vías de desarrollo?}

La corrupción tiene como causa la crisis de valores que existe en el mundo. Una visión en la que se antepone el bien individual al común; en la que los seres humanos no son considerados personas, sino consumidores; la familia ya no es la base de la sociedad, sino la empresa. En los países desarrollados la acumulación de riquezas, el éxito personal, la capacidad de consumo; justifica violar la ley.

Por ejemplo: Odebrecht, siendo una empresa de alto nivel en ingeniería, preparada para concursar y ganar obras públicas; decide lograr una posición hegemónica creando un gran sistema de corrupción política y empresarial a nivel internacional. En los países en vías de desarrollo la misma visión produce graves problemas de institucionalidad que permiten la corrupción; un mal endémico o estructural de la sociedad.

2. ¿Considera que la corrupción representa simplemente a un tema político, o cree que responde a una larga historia de nuestro país y representa temas culturales estructuralmente establecidos?

En el Perú la corrupción no afecta sólo la política, es un problema endémico o estructural de la sociedad, forma parte de la vida cotidiana; la crisis de valores hace de la corrupción, esto es, de la deshonestidad, una forma de vivir, parte de una cultura de ilegalidad. Lamentablemente, en el país, la violación de la ley es la regla, el cumplimiento es la excepción.

3. ¿Qué rol juega el Derecho penal en la lucha contra la corrupción? ¿Cuál es el bien jurídico protegido en los delitos contra la Administración Pública?

El derecho penal en sentido amplio cumple función preventiva y represiva. Frente a la corrupción, el derecho procesal penal permitirá determinar las causas de la corrupción en la administración pública, en la contratación estatal, a fin de promover la adopción de políticas preventivas frente a las causas de la corrupción. El derecho penal, a través de la pena, busca producir prevención general positiva y negativa; con dura penalidad trata de generar en las personas los efectos de reestablecer la confianza en la ley y de disuasión a incurrir en prácticas de corrupción. Pero advierto que el derecho penal es un medio, una de las herramientas en las cuales el Estado debe lograr eficacia para realmente enfrentar la corrupción.

El objeto genérico de protección penal es el correcto funcionamiento de la administración pública; y el objeto específico hay que buscarlo 
en los distintos tipos penales correspondientes a los delitos contra la administración Pública.

4. ¿Cuál es nuestra regulación peruana en materia anticorrupción? En su opinión, ¿considera suficiente la actual legislación penal anticorrupción?

En lo que corresponde al ámbito penal, el Código de 1991 en el Libro Segundo, Título XVIII, Capítulo Segundo, regula los delitos cometidos por funcionarios públicos. La legislación penal se ha potenciado con la incorporación del delito de corrupción privada dentro de los artículos 241-A y 241-B, cuyos efectos sobre este tipo de crimen aún no se han establecido.

La corrupción privada se ha incorporado como delitos económicos; en la medida que se generen casos y sanciones penales se irá demostrando cómo comportamientos tolerados socialmente, incluso considerados "legales", son formas criminales de corrupción entendida en el amplio sentido que establece el derecho internacional, que abarca la cometida en el ámbito público y en el privado.

5. Observamos casos de funcionarios públicos que presentan los medios de comunicación en el país, incluyendo expresidentes y exalcaldes con prisión preventiva. En su opinión ¿cómo considera que se están llevando los procesos en el país?

Los denominados casos Lava Jato corresponden a una tercera "gran ola" del derecho penal y procesal penal, que a mi generación ha tocado vivir. a) Sistema de Justicia Antiterrorista; primera versión del Sistema de Justicia Anticorrupción por los casos vinculados al gobierno del ex presidente Alberto Fujimori; y b) la segunda versión del Sistema de Justicia Anticorrupción por los casos generados con la penetración de la empresa y política brasileña en la administración pública del Perú, el sector empresarial; principalmente en el ámbito de la gran construcción, y los partidos políticos.
Siempre, las "grandes olas" en materia penal son expresiones del llamado derecho penal y procesal penal del enemigo; la demanda de castigo, justicia, venganza, o simplemente reacción social frente a un alto nivel de criminalidad reciente. Del mismo modo, en las bases del Estado de Derecho se sacrifican las garantías sobre las que se construye el proceso penal y la correcta aplicación de la ley penal; además de instituciones débiles, Poder Judicial, Policía Nacional, Colegio de Abogados, la misma que se ve agravada por los también mega casos conocidos como los "CNM Audios"; "Cuellos Blancos", o "los Audios de la Vergüenza".

Las investigaciones evidencian abuso de la detención preliminar y la prisión preventiva. La Corte Suprema y el Tribunal Constitucional tratan de frenar el caso de la prisión preventiva, pero aún están sin trabajo jurisprudencial alguno. El caso de la detención preliminar constituye una privación de la libertad, que por su corto plazo no deja de ser grave, pues recae sobre personas que ni siquiera tienen la condición de procesadas; convirtiéndose en armas para doblegar voluntades y presionar celebración de acuerdos de colaboración eficaz, cuyo origen termina siendo muy discutible por el vicio de la voluntad que genera la coacción. Hay que recordar que la colaboración eficaz es justicia negociada, convenios de colaboración penal, necesariamente voluntarios.

Las nuevas técnicas de investigación, como la interceptación de las comunicaciones telefónicas, también están en una hora de control de constitucionalidad y legalidad en el Caso de los "Cuellos Blancos", particularmente en las escuchas de terceras personas con o sin autorización judicial.

Los juicios y las sentencias definirán debates, confío en el trabajo de los jurídicos, sobre la criminalización de las donaciones electorales anónimas y el delito de lavado de activos, de aún muy incipiente jurisprudencia. 